\title{
Bronchodilatation increases number of particles in exhaled air in subjects with asthma
}

\author{
Anna-Carin Olin ${ }^{1 *}$,Emilia Viklund ${ }^{1}$, Per Larsson ${ }^{1}$, Ann-Charlotte Almstrand ${ }^{1}$, Anna Bredberg ${ }^{1}$, \\ Ekaterina Mirgorodskaya', Björn Bake ${ }^{2}$ \\ From EAACI International Severe Asthma Forum (ISAF 2012) \\ Gothenburg, Sweden. 11-13 October 2012
}

\section{Background}

Particles in exhaled air (PEx) are derived from the small airways and are formed during airway closure and re-opening. They mainly contain surfactant; both phospholipid and protein composition in PEx resemble that of BAL. Measurements of surfactant protein A in PEx from $100 \mathrm{l}$ exhaled air were shown to be highly reproducible, making the PEx a promising tool in the monitoring of asthma. The number of exhaled particles varies substantially, mainly among subjects, but also within subjects. To enable a correct interpretation of the results using PEx it is crucial to examine how airway constriction affects the number of exhaled particles.

\section{Aim}

To examine the effect of bronchodilatation on exhaled PEx concentration.

\section{Method}

16 subjects with pollen-asthma and 14 healthy non-atopic subjects (all non-smokers) were examined before and after bronchodilation during the pollen season and outside the pollen-season. PEx, spirometry, blood-samples and answers to a questionnaire were obtained. The subjects performed a breathing maneuvers allowing for airway closure and re-opening and PEx concentrations in about $60 \mathrm{l}$ of exhaled air were measured with an in-house developed instrument based on particle impaction.

\section{Results}

PEx concentrations were not significantly different between asthmatics and controls but asthmatics showed lower PEx concentrations during pollen season compared to outside pollen season ( $3.46 \mathrm{v}$ s $4.32 \mathrm{p}=0.01)$ whereas controls showed non-significant differences between seasons (6.86 v s $4.54 \mathrm{p}=0.15)$. PEx concentrations increased after bronchodilatation in asthmatics (median $4.05^{*} 103$ to $4.92 * 103, \mathrm{p}=0.02$ ), but not in controls (median $4.47^{*}$ 103 v s $4.50 * 103 \mathrm{p}=0.12$ ). The change in PEx concentration (\%) was associated with the change in FVC (\%) (rp= $0.51, \mathrm{p}=0.001)$ and FEV1 ( $\mathrm{pp}=0.46, \mathrm{p}=0.003)$ among subjects with asthma whereas there were no significant correlations among controls.

\section{Conclusion}

In the present study the subjects had mild symptoms and rather low reversibility also during pollen-season. Nevertheless, PEx concentrations were apparently influenced by bronchomotor tone and increased after bronchodilatation, presumably reflecting increased airway opening following bronchodilatation in asthmatics with ongoing airway inflammation.

\footnotetext{
Author details

${ }^{1}$ Gothenburg University, Occupational and Environmental Medicine, Sweden. ${ }^{2}$ Gothenburg University, Dept of Respiratory Medicine and Allergology, Sweden.

Published: 3 May 2013

doi:10.1186/2045-7022-3-S1-P12

Cite this article as: Olin et al:: Bronchodilatation increases number of particles in exhaled air in subjects with asthma. Clinical and Translational Allergy 2013 3(Suppl 1):P12.
} 